\title{
Genetic evidence that Weissella kimchii Choi et al. 2002 is a later heterotypic synonym of Weissella cibaria Björkroth et al. 2002
}

\author{
Saïd Ennahar and Yimin Cai \\ National Institute of Livestock and Grassland Science, Department of Animal Feeding and \\ Management, Nishinasuno, Tochigi 329-2793, Japan
}

Correspondence

Yimin Cai

cai@affrc.go.jp
The genus Weissella consists of a group of heterofermentative Leuconostoc-like lactic acid bacteria (Collins et al., 1993). It is proposed that the following 12 species be included in the genus: Weissella confusa, Weissella halotolerans, Weissella hellenica, Weissella kandleri, Weissella minor, Weissella paramesenteroides, Weissella viridescens (Collins et al., 1993), Weissella thailandensis (Tanasupawat et al., 2000), Weissella cibaria (Björkroth et al., 2002), Weissella kimchii (Choi et al., 2002), Weissella soli (Magnusson et al., 2002) and Weissella koreensis (Lee et al., 2002).

In a recent study, while investigating lactic acid bacteria inhabiting paddy rice silage in Japan, we reported the presence of isolates belonging to the genus Weissella (Ennahar et al., 2003). On the basis of an analysis of the $16 \mathrm{~S}$ rDNA sequences, strain RO5 appeared to be very closely related to the type strains of $W$. kimchii and $W$. cibaria, suggesting a close phylogenetic affiliation between these species. W. kimchii was isolated from a traditional fermented vegetable in Korea (Choi et al., 2002), whereas $W$. cibaria originated from a traditional unfermented food ingredient in Malaysia (Björkroth et al., 2002). Although separate studies clearly distinguished the two species from

Published online ahead of print on 13 October 2003 as DOI 10.1099/ ijs.0.02783-0.

The GenBank accession number for the $16 \mathrm{~S}$ rDNA sequence of strain $\mathrm{RO5}$ is AF515221.

A phylogenetic tree constructed using a larger data set than shown in Fig. 1, details of acid production from carbohydrates (Table I) and DNA-DNA reassociation data (Table II) are available in IJSEM Online. other members of the genus Weissella on the basis of their phenotypic and phylogenetic characteristics (Björkroth et al., 2002; Choi et al., 2002), a comparative investigation including both species has yet to be carried out.

The present study set out to identify strain RO5, isolated from paddy rice silage, and to investigate whether $W$. cibaria and W. kimchii are phylogenetically different. Comparative $16 \mathrm{~S}$ rDNA sequence and DNA-DNA hybridization analyses as well as a physiological analysis were carried out. Since Weissella spp. are relatively common in Japanese rice silage (Cai et al., 1994, 1998; Ennahar et al., 2003), our study is also interesting from an ecological point of view.

The Weissella type strains used in the present study are shown in Fig. 1. Strain RO5 was isolated previously from paddy rice silage (Ennahar et al., 2003). Bacterial cultures were grown on MRS agar (Difco) at $30^{\circ} \mathrm{C}$ for $24 \mathrm{~h}$, before being transferred to nutrient broth (Difco) with $10 \%$ glycerol and stored as stock cultures at $-80^{\circ} \mathrm{C}$ for further analysis.

Strain RO5 was compared with type strains of Weissella species by using carbohydrate assimilation/fermentation on API $50 \mathrm{CH}$ strips (bioMérieux), as described previously (Ennahar et al., 2003). RO5 displayed fermentation patterns matching those of W. cibaria LMG $17699^{\mathrm{T}}$ and W. kimchii DSM $14295^{\mathrm{T}}$. The three strains produced acid from D-fructose, D-glucose, D-mannose, $\mathrm{N}$-acetylglucosamine, amygdalin, arbutin, salicin, cellobiose, maltose and sucrose (see Table I, supplementary data), and hydrolysed aesculin. Weak acid production was observed with $\beta$-gentiobiose and gluconate. Mannitol, methyl $\alpha$-D-glucoside, melibiose, 


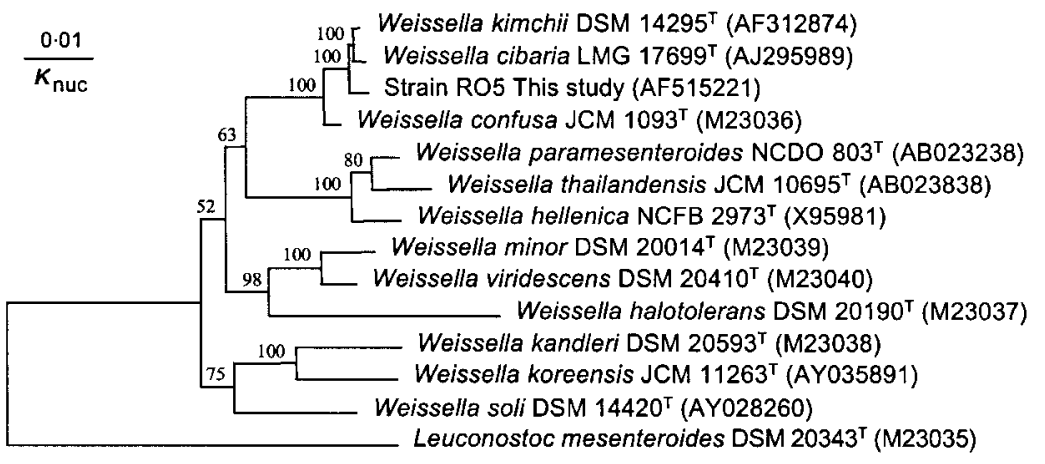

Fig. 1. Phylogenetic tree showing the relative positions of strain $\mathrm{RO} 5$ and Weissella species as inferred by the neighbour-joining method for $16 \mathrm{~S}$ rDNA sequences. Bootstrap values for a total of 100 replicates are shown at the nodes of the tree. References of the type strains used for comparison are given, as well as the accession numbers for all 16S rDNA sequences (in parentheses). Leuconostoc mesenteroides was used as an outgroup. Bar, $1 \%$ sequence divergence. A phylogenetic tree constructed using a larger data set can be found in IJSEM Online. trehalose, melezitose, D-turanose and D-arabitol were not fermented. Variable reactions were obtained with L-arabinose, ribose, D-galactose and $\mathrm{D}$-xylose, which revealed differences involving weak reactions.

The lactic acid configuration was determined enzymically using a test kit from Boehringer, as described previously (Cai et al., 1998). Strain RO5, W. cibaria LMG $17699^{\mathrm{T}}$ and W. kimchii DSM $14295^{\mathrm{T}}$ produced more than $90 \%$ of their lactic acid in the D-isomer form.

Amplification, purification and sequencing were performed as described previously (Ennahar et al., 2003). The virtually complete RO5 16S rDNA sequence was used to search Ribosomal Database Project II. The highest level of sequence similarity, 99.4\%, was found with W. kimchii and W. cibaria. Additionally, type strains from these two species showed an overall level of sequence similarity of $99.7 \%$ (1491 out 1496 bases were identical). On the basis of the $16 \mathrm{~S}$ rDNA sequences, phylogenetic trees were constructed by using the neighbour-joining method, as described previously (Ennahar et al., 2003). This analysis placed strain RO5 in the same cluster as W. kimchii and W. cibaria, and confirmed its equally close relationship to both species (Fig. 1).

W. cibaria LMG $17699^{\mathrm{T}}$ and W. kimchii DSM $14295^{\mathrm{T}}$, as well as type strains from somewhat more distant species, were chosen as reference strains for DNA-DNA hybridization experiments with strain RO5 (see Table II, supplementary data). Chromosomal DNA was purified by using standard methods (Sambrook et al., 1989), as modified by Satomi et al. (1997). DNA-DNA relatedness was studied by the method of Ezaki et al. (1989) using photobiotin labelling and colorimetric detection. The results for strain RO5 showed reassociation levels of $97 \cdot 3$ and $98 \cdot 6 \%$ with W. cibaria LMG $17699^{\mathrm{T}}$ and W. kimchii DSM $14295^{\mathrm{T}}$, respectively. In addition, the level of DNA relatedness between the type strains of $W$. cibaria and $W$. kimchii was $98 \cdot 2 \%$. This is far higher than the DNA reassociation threshold value recommended for species delineation (70\%) (Wayne et al., 1987). Both species, however, showed less than $40 \%$ relatedness with other members of the genus Weissella, with the exception of $W$. confusa (43-53\%).
DNA base content was determined by the method of Tamaoka \& Komagata (1984) using HPLC, as described previously (Ennahar et al., 2003). The mean G+C content of the DNA of strain RO5 was $48.5 \mathrm{~mol} \%$, which is comparable to the corresponding published values for $W$. kimchii and $W$. cibaria, i.e. $48 \cdot 2$ and $44-45 \mathrm{~mol} \%$, respectively (Björkroth et al., 2002; Choi et al., 2002).

As described above, phenotypic characterization, 16S rDNA sequence analysis, DNA-DNA hybridization and G+Ccontent determination showed that strain RO5, isolated from paddy rice silage, should be classified within the genus Weissella, with $W$. cibaria and $W$. kimchii as its nearest phylogenetic relatives. More importantly, on the basis of the detailed phenotypic and genetic characteristics, we could find no significant differences to justify separation of the type strains W. kimchii DSM $14295^{\mathrm{T}}$ and W. cibaria LMG $17699^{\mathrm{T}}$. Therefore, given the earlier publication of the $W$. cibaria description, we propose that $W$. kimchii (Choi et al., 2002) is a later heterotypic synonym of $W$. cibaria (Björkroth et al., 2002) and consequently should be renamed.

\section{References}

Björkroth, K. J., Schillinger, U., Geisen, R., Weiss, N., Hoste, B., Holzapfel, W. H., Korkeala, H. J. \& Vandamme, P. (2002). Taxonomic study of Weissella confusa and description of Weissella cibaria sp. nov., detected in food and clinical samples. Int J Syst Evol Microbiol 52, 141-148.

Cai, Y., Ohmomo, S. \& Kumai, S. (1994). Distribution and lactate fermentation characteristics of lactic acid bacteria on forage crops and grasses. J Jpn Soc Grassl Sci 39, 420-428.

Cai, Y., Benno, Y., Ogawa, M., Ohmomo, S., Kumai, S. \& Nakase, T. (1998). Influence of Lactobacillus spp. from an inoculant and of Weissella and Leuconostoc spp. from forage crops on silage fermentation. Appl Environ Microbiol 64, 2982-2987.

Choi, H.-J., Cheigh, C.-I., Kim, S.-B., Lee, J.-C., Lee, D.-W., Choi, S.-W., Park, J.-M. \& Pyun, Y.-R. (2002). Weissella kimchii sp. nov., a novel lactic acid bacterium from kimchi. Int J Syst Evol Microbiol 52, 507-511.

Collins, M. D., Samelis, J., Metaxopoulos, J. \& Wallbanks, S. (1993). Taxonomic studies on some leuconostoc-like organisms 
from fermented sausages: description of a new genus Weissella for the Leuconostoc paramesenteroides group of species. J Appl Bacteriol 75, 595-603.

Ennahar, S., Cai, Y. \& Fujita, Y. (2003). Phylogenetic diversity of lactic acid bacteria associated with paddy rice silage as determined by 16 S ribosomal DNA analysis. Appl Environ Microbiol 69, 444-451.

Ezaki, T., Hashimoto, Y. \& Yabuuchi, E. (1989). Fluorometric deoxyribonucleic acid-deoxyribonucleic acid hybridization in microdilution wells as an alternative to membrane filter hybridization in which radioisotopes are used to determine genetic relatedness among bacterial strains. Int J Syst Bacteriol 39, 224-229.

Lee, J.-S., Lee, K. C., Ahn, J.-S., Mheen, T.-I., Pyun, Y.-R. \& Park, Y.-H. (2002). Weissella koreensis sp. nov., isolated from kimchi. Int J Syst Evol Microbiol 52, 1257-1261.

Magnusson, J., Jonsson, H., Schnürer, J. \& Roos, S. (2002). Weissella soli sp. nov., a lactic acid bacterium isolated from soil. Int J Syst Evol Microbiol 52, 831-834.
Sambrook, J., Fritsch, E. F. \& Maniatis, T. (1989). Molecular Cloning: a Laboratory Manual, 2nd edn. Cold Spring Harbor, NY: Cold Spring Harbor Laboratory.

Satomi, M., Kimura, B., Mizoi, M., Sato, T. \& Fujii, T. (1997). Tetragenococcus muriaticus sp. nov., a new moderately halophilic lactic acid bacterium isolated from fermented squid liver sauce. Int J Syst Bacteriol 47, 832-836.

Tamaoka, J. \& Komagata, K. (1984). Determination of DNA base composition by reversed-phase high-performance liquid chromatography. FEMS Microbiol Lett 124, 11-16.

Tanasupawat, S., Shida, O., Okada, S. \& Komagata, K. (2000). Lactobacillus acidipiscis sp. nov. and Weissella thailandensis sp. nov., isolated from fermented fish in Thailand. Int J Syst Evol Microbiol 50, 1479-1485.

Wayne, L. G., Brenner, D. J., Colwell, R. R. \& 9 other authors (1987). International Committee on Systematic Bacteriology. Report of the ad hoc committee on reconciliation of approaches to bacterial systematics. Int J Syst Bacteriol 37, 463-464. 